\title{
Predictive torque and flux control of an induction machine drive using fuzzy multi-criteria decision making
}

\author{
VIKAS KUMAR*, PRERNA GAUR and A P MITTAL \\ Division of Instrumentation and Control Engineering, Netaji Subhas Institute of Technology, New Delhi, India \\ e-mail: sainivika@gmail.com
}

MS received 9 February 2015; revised 28 August 2016; accepted 10 November 2016

\begin{abstract}
Among the numerous direct torque control techniques, the finite-state predictive torque control (FSPTC) has emerged as a powerful alternative as it offers the fast dynamic response and the flexibility to optimize multiple objectives simultaneously. However, the implementation of FS-PTC for multiple objectives optimization requires the optimization of a single objective function, which is constructed using weighting factors as a linear combination of individual objective functions. Traditionally, the weighting factors are determined through a non-trivial process, which is a complex and time-consuming task. In an effort to avoid the timeconsuming task of weighting factor selection, this paper aims at replacing the weighting factor calculation with a systematic fuzzy multiple-criteria decision making in which the individual objective functions may have equal or varying degrees of importance. As a result the weighting factor calculation can be completely avoided. The simulation and experimental tests are conducted on a $2.2 \mathrm{~kW}$ induction motor drive to validate the proposed approach. The result outcomes are compared with the conventional predictive torque control (PTC) using weighting factors on the same experimental platform.
\end{abstract}

Keywords. Finite-state model predictive control; fuzzy decision making; multi-objective optimization; predictive torque control.

\section{Introduction}

For high dynamic servo control, direct torque control (DTC) is an indispensable control method, due to its simple implementation, low computational time and reduced parameter sensitivity $[1,2]$. However the conventional DTC is implemented using a torque and flux hysteresis controller, which causes large torque ripples as compared with the field oriented control (FOC) [3]. In order to reduce the torque ripples, several modifications to the conventional DTC scheme like space-vector-modulation-based DTC (SVMDTC), sliding-mode-based SVM-DTC, fuzzy-logic-based variable duty cycle DTC and predictive torque control (PTC) [4-6] have been proposed. In the recent years, due to the advent of high-speed digital signal processors (DSPs) the PTC has emerged as a powerful alternative to the control of power converters and electrical drives due to its fast dynamic response, flexibility to include multiple objectives and easy inclusion of system constraints and plant non-linearity [7-9]. PTC has been implemented using a discrete model of the converter that is evaluated for each possible actuation and a cost function based upon the desired control objective is optimized in every sampling period linearity [19]. However, for applications where more than one control objectives are

*For correspondence desired to be met, a single cost function or aggregate objective function (AOF) that represents the desired behaviour is created using weighting factors as a linear combination of individual objective functions. The AOF is evaluated for every possible switching state and the switching state that minimizes the AOF is applied in the next sampling instant [8, 19]. The determination of these weighting factors for a given objective function is a complex and time-consuming task due to the different natures of individual objective functions.

Traditionally the weighting factors are determined analytically and no systematic design guidelines have been reported. Some weighting factor determination guidelines can be found in Cortes et al [10] as proposed by them, in which the branch and bound algorithm is effectively used for multi-objective optimization. However the branch and bound algorithm is an offline procedure and is tough to perform. The computational complexity of the algorithm increases as the number of objective functions increases. Rojas et al [11] used a ranking-based method for multi-objective optimization. Using the ranking-based method, the branch and bound algorithm is completely avoided, but the ranking-based method requires sorting of the individual objective functions or the error values, which require significant computational burden. The computational burden depends upon the sorting algorithm used and it can be demanding if more than two 
objective functions are considered. Moreover, in the rankingbased method, the actual value of the cost function is replaced by a rank; hence comparison may not reflect how far or close two adjacent ranked switching functions are. Same ranks for two objective functions are tough to resolve as they may have two different cost function values. The analytical hierarchical process proposed by Saaty [12] depends on the crisp value and is used by many researchers. However the determination of crisp value for a given objective function is not straightforward. The alternative approach to the empirical and offline procedures for weighting factor selection can be the fuzzy multiple-criteria decision making (FMCDM). The FMCDM approach is applied successfully in various fields for optimizing multiple and conflicting objectives [13-16].

The objective of this study is to replace the weighting factor tuning problem in model-predictive DTC with a systematic procedure. The multiple-criteria optimization problem is addressed using FMCDM in which the individual objective function is evaluated for all possible switching states. The evaluated objective function is fuzzified using a linear membership function and then the max-min inference method is used to calculate the optimized switching state. The proposed method is validated with the help of simulation and experimental results of a $2.2 \mathrm{~kW}$ induction motor. The performance of the proposed approach is evaluated and compared to the conventional MPC-based multi-objective optimization technique.

The rest of the paper is organized as follows. In section 2, the discrete time modelling of IM and PTC algorithm is presented. Section 3 deals with the proposed multiple objective optimizations algorithm, the conventional PTC-based multi-objective optimization. Introduction to the experimental set-up and implementation details are presented in section 4 . The simulation and experimental results together with algorithm complexity are discussed in section 5. Conclusions are presented in section 6 .

\section{Discrete time modelling and predictive torque and flux control}

The induction motor model in the stator reference frame is characterized by the following equations [17]:

$$
\begin{gathered}
u_{s}=R_{s} i_{s}+\frac{d \Phi_{s}}{d t} \\
u_{r}=R_{r} i_{r}+\frac{d \Phi_{r}}{d t}-j \omega \Phi_{r}=0 \\
\Phi_{s}=L_{s} i_{s}+L_{m} i_{r} \\
\Phi_{r}=L_{r} i_{r}+L_{m} i_{s} \\
T=\frac{3}{2} * p * \operatorname{Im}\left(\Phi_{s}^{*} i_{s}\right)
\end{gathered}
$$

$$
J \frac{d \omega_{m}}{d t}=T-T_{L}
$$

where $\omega$ is the electrical angular speed and $\omega_{m}$ is the rotor mechanical speed $\left(\omega=p \omega_{m}\right) ; i_{s}, \Phi_{s}$ and $R_{s}$ are the stator current, stator flux and stator resistance, respectively; $i_{r}, \Phi_{r}$ and $R_{r}$ are the rotor current, rotor flux and rotor resistance, respectively, $T$ is the electromagnetic torque, $p$ is the number of pole pairs, $J$ is the moment of inertia, $u_{s}$ and $u_{r}$ are the stator and the rotor voltage, respectively, and $T_{L}$ is the load torque.

The predictive torque and flux control requires prediction of the torque and flux variables. Choosing stator current and rotor flux as state variables, the predicted values of the stator current and the rotor flux are derived as follows.

Discretizing Eq. (1) using forward Euler's approximation:

$$
\begin{gathered}
u_{s}(k)=R_{s} i_{s}(k)+\frac{\Phi_{s}(k)-\Phi_{s}(k-1)}{T_{s}}, \\
T_{s} \text { is the sampling time. }
\end{gathered}
$$

Equation (7) can be rearranged to calculate $\Phi_{s}(k)$ as follows:

$$
\Phi_{s}(k)=\Phi_{s}(k-1)-T_{s} R_{s} i_{s}(k)+T_{s} u_{s}(k) .
$$

The predicted value of the stator flux $\Phi_{s}^{p}(k+1)$ using Eq. (8) is given as

$$
\Phi_{s}^{p}(k+1)=\Phi_{s}(k)-T_{s} R_{s} i_{s}(k)+T_{s} u_{s}(k) .
$$

The predicted value of the stator current is calculated using the stator current and the rotor flux as state variables. Using the Joachim Holtz [17] state model, the dynamics of the induction machine is described by the following equations:

$$
\begin{gathered}
\tau_{\sigma} \frac{d i_{s}}{d t}+i_{s}=\frac{k_{r}}{R_{\sigma}}\left(\frac{1}{\tau_{r}}-j \omega\right) \Phi_{r}+\frac{u_{s}}{R_{\sigma}} \\
\Phi_{r}+\tau_{r} \frac{d \Phi_{r}}{d t}=j \omega \Phi_{r} \tau_{r}+L_{m} i_{s}
\end{gathered}
$$

where $\quad \tau_{r}=\frac{L_{r}}{R_{r}}, \quad \sigma=1-\frac{L_{m}^{2}}{L_{s} L_{r}}, \quad k_{r}=\frac{L_{m}}{L_{r}}, \quad k_{s}=\frac{L_{m}}{L_{s}}$, $R_{\sigma}=R_{s}+R_{r} k_{r}^{2}, \tau_{\sigma}=\frac{\sigma L_{s}}{R_{\sigma}}$.

Discretizing Eqs. (10) and (11), using forward Euler's approximation, the predicted value of the rotor flux and stator current $\left(i_{s}^{p}(k+1)\right)$ can be obtained as follows:

$$
\left.\begin{array}{c}
\Phi_{r}^{p}(k)=\frac{L_{r}}{L_{m}} \Phi_{s}^{p}(k)+i_{s}(k)\left(L_{m}-\frac{L_{s} L_{r}}{L_{m}}\right) \\
i_{s}^{p}(k+1)=\left(1-\frac{T_{s}}{\tau_{\sigma}}\right) i_{s}(k)+\frac{T_{s}}{\tau_{\sigma}}\left\{\frac{1}{R_{\sigma}}\left[\left(\frac{k_{r}}{\tau_{r}}-k_{r} j \omega\right) \Phi_{r}(k)+u_{s}(k)\right]\right\}
\end{array}\right\} .
$$

Using Eqs. (5), (9) and (12) the predicted value of the torque is written as follows: 


$$
T^{p}(k+1)=\frac{3}{2} p \operatorname{Im}\left\{\overline{\Phi_{s}^{p}(k+1)} i_{s}^{p}(k+1)\right\} .
$$

The three-phase stator current is measured and is used to predict the future values of torque and flux. The line diagram for the PTC strategy is shown in figure 1.

The torque and flux values are predicted for sampling time $t=k+1$, using Eqs. (9), (12) and (13). A single cost function for sampling time $t=k+1$ is formed from the torque error and the flux error as given in Eq. (14) using weighting factors:

$$
\left.\begin{array}{l}
g_{1}(k+1)=\left|T^{r}-T^{p}(k+1)\right| \\
g_{2}(k+1)=\left|\Phi_{s}^{r}-\Phi_{s}^{P}(k+1)\right|
\end{array}\right\}
$$

where $\Phi_{s}^{r}$ and $T^{r}$ are the reference stator flux and the reference torque, respectively; $\Phi_{s}^{P}$ and $T^{p}$ are the predicted values of the stator flux and torque, respectively. The cost functions $g_{1}$ and $g_{2}$ as defined in Eq. (14) are added using weighting factors

$$
g(k+1)=\left|T^{r}-T^{p}(k+1)\right|+\lambda_{\Phi}\left|\Phi_{s}^{r}-\Phi_{s}^{P}(k+1)\right|
$$

where $\lambda_{\Phi}$ is the weighting factor associated with the flux error.

In PTC the future values of flux and stator currents are predicted using Eqs. (9) and (12), respectively, for seven distinct switching states of the inverter. The future value of the torque is predicted for each predicted value of the flux and the stator current using Eq. (13). Finally, the switching state selection is made by optimizing a single cost function, which contains the control law. The cost function corresponds to a comparison between the flux and torque references to their predicted values. The single cost function as defined in Eq. (15) is evaluated for all switching states and the switching state that minimizes the cost function, i.e., the torque error and the flux error, is chosen as the optimized state. This switching state is used to generate the firing pulses to the inverter. The speed error is used to calculate the reference torque; the predict block is used to predict the values of flux, stator current and torque. The minimization block calculates the optimized switching state corresponding to the minimum value of the cost function.

\subsection{Delay compensation in predictive torque control}

Performance of the PTC is significantly affected by the delay that is introduced due to calculations as implementation of finite-state PTC requires prediction of future states of the stator flux, rotor flux and stator current. The delay compensation algorithm in a finite-state predictive current control algorithm is implemented for a two-level voltage source inverter by Kumar et al [18]. In their work, the future states of the load current and back emf are predicted using a model of the load and the current tracking performance is improved due to delay compensation. The cause of delay and timing of various tasks is explained as follows: (1) measure load currents, (2) apply the new switching state, (3) stator flux and rotor flux prediction and (4) load current prediction and selection of optimal switching state. Effect of voltage vector is visible at time $k+2$ as shown in figure 2. The stator

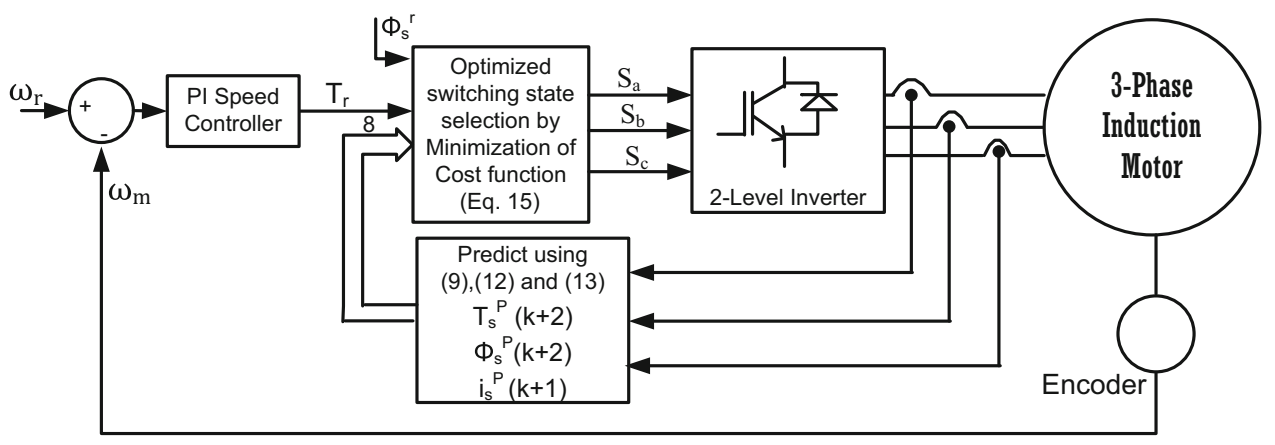

Figure 1. Line diagram for predictive torque and flux control.
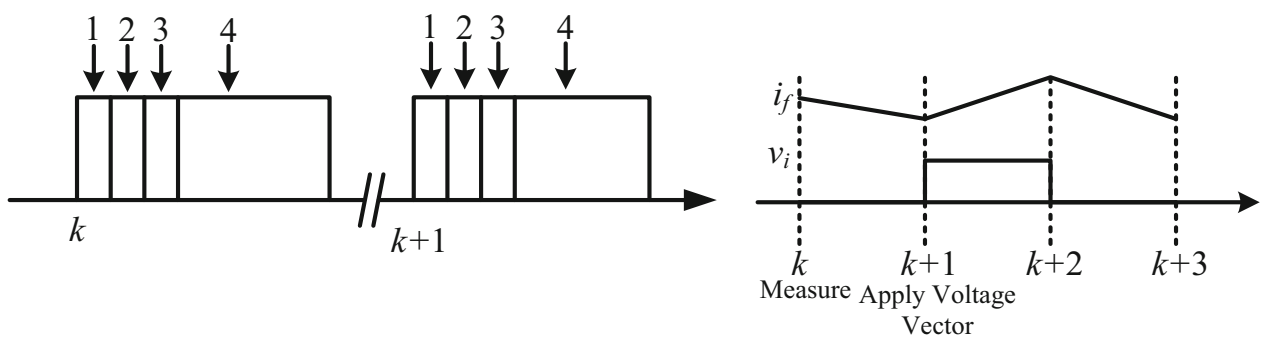

Figure 2. Timing of various tasks in delay compensation. 
current $i_{s}(k+1)$ and stator flux $\Phi_{s}(k+1)$ are estimated using previously calculated $u(k)$, measured current $i_{s}(k)$ and stator flux $\Phi_{s}(k)$. In order to compensate the calculation delay in the present work, the future states of the stator flux, rotor flux and stator current are predicted for time $t=k+2$ using $u(k+1), i_{s}(k+1)$ and $\Phi_{s}(k+1)$. The cost function will be modified as per (16).

$$
g(k+2)=\left|T^{r}-T^{p}(k+2)\right|+\lambda_{\Phi}\left|\Phi_{s}^{r}-\Phi_{s}^{P}(k+2)\right| .
$$

\section{Multiple-objective optimization}

As explained in the previous section, the implementation of FS-PTC of an induction machine drive requires selection of the switching state that minimizes the single cost function as defined in Eq. (16) or this is equivalent to the simultaneous optimization of two objective functions namely the torque and the flux error. The minimization of single cost function requires the determination of weighting factor $\lambda_{\Phi}$, which is calculated using the branch and bound algorithm. However, the calculation of weighting factor is a complex and timeconsuming task. The fuzzy-logic-based multiple-criteria decision making is presented as an alternative to the weighting-factor-tuning-based method in the following section.

\subsection{Branch and bound algorithm}

The AOF or single cost function as given in Eq. (16) is used for optimization. The PTC requires two objective functions, i.e., torque error and the flux error, to be minimized simultaneously. The two objective functions cannot be directly added owing to the different nature of the objective functions. The different objective functions are added by means of weighting factors, which represents the relative importance of individual objective functions. The higher the value of the weighting factor, higher the importance of that particular objective function, and a zero value of weighting factor represents no contribution of that particular objective function. The weighting factors are calculated using the branch and bound algorithm. The branch and bound algorithm for two objective functions $g_{1}$ and $g_{2}$ is shown in figure 3 . The implementation procedure of branch and bound algorithm requires desired measures (desired performance parameters) to be defined for each objective function. The algorithm starts with four different values of the weighting factors $\lambda_{1}=0, \lambda_{2}=1, \lambda_{3}=10$ and $\lambda_{4}=100$. Simulations are carried out for the objective function given in Eq. (16) for the mentioned values of $\lambda$. The measures of the objective function $\left(C_{1}\right.$ and $\left.C_{2}\right)$ corresponding to different values of $\lambda$ are compared to the desired measures of the control strategy, which are specified for the application like current error and switching frequency in this case. Let desired measures lie in the interval $\lambda_{1}$ and $\lambda_{2}$. The $\lambda$ is modified as the average of $\lambda_{1}$

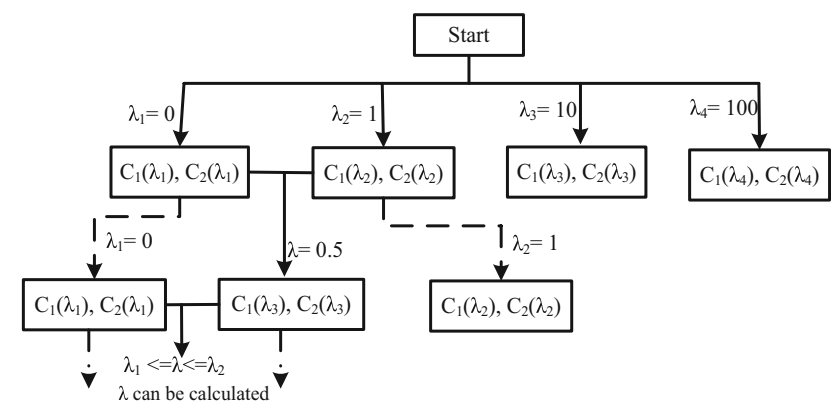

Figure 3. Branch and bound algorithm.

and $\lambda_{2}$, which is 0.5 . Again the simulations are carried out for the objective function given in Eq. (15) for $\lambda_{1}, \lambda_{2}$ and $\lambda$. Let this time the minimum value of the desired outcomes lie between $\lambda_{1}$ and $\lambda$, i.e., $0<=\lambda<=0.5 ; \lambda$ is modified to 0.25 . This procedure is repeated till we get the minimum value of the measures, i.e., $\lambda_{\Phi}[19]$.

\subsection{Fuzzy multi-criteria decision making}

Multi-criteria decision making is related to making the best decision in the presence of probabilistic uncertainty and vagueness, which is a difficult task if the goals and constraints are specified in terms of crisp values. The application of fuzzy logic to the multi-criteria decision making problem replaces the crisp goals and constraints with their fuzzy equivalents. The determination of fuzzy goals and constraints for a particular objective function is comparatively simple and straightforward and hence FMCDM has been applied extensively in various engineering and nonengineering fields for decision making where multiple and conflicting objectives must be met. The FMCDM is based upon the following definition by Bellman and Zadeh [20].

The FMCDM is characterized by the membership function that associates with each point a real number in the interval $[0,1]$. This real number, also known as membership value, represents the degree of attainment of the goals. After fuzzification, each cost function varies in the range $[0,1]$. These resulting values of the cost functions are compatible and can be directly compared. Linear mapping is used in this work so as to have a low computational burden [13, 16, 21].

For the present work, the commonly used linear membership function as shown in figure 4 is used for fuzzification of individual objective functions. The linear membership function used for the present work is defined as follows:

$$
\begin{aligned}
& \mu_{j}\left(S_{j}^{k+1}\right)=\left\{\frac{g_{i}^{k+2(\max )}-g_{i}^{k+2}\left(S_{j}^{k+1}\right)}{g_{i}^{k+2(\max )}-g_{i}^{k+2(\min )}}\right. \\
& j=0,1, \ldots, 7 \text { (number of switching states) } \\
& \text { and } i=1,2, \ldots, n \text { (number of objective functions), }
\end{aligned}
$$




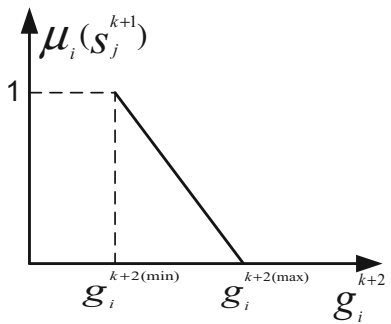

Figure 4. Linear membership function.

where $\mu_{i}$ is the $i$ th goal membership function; $g_{i}^{k+2(\max )}$ and $g_{i}^{k+2(\min )}$ are the maximum and minimum value of the objective function $g_{i}$ at sampling instant $k+2$. It can be observed from Eq. (17) that the mapping varies for each sampling instant depending upon the cost function and the system requirements. The scale for each cost function is variable and the possible level of achievement of goal is considered. Direct comparisons can be made between different objective functions. The importance of the different objective functions is specified by the designer of the strategy.

For equally important objective function, the final decision is the maximizing decision function given by the maximum of the intersection defined as follows:
$\mu_{D}\left(S_{j}^{k+1}\right)=\min \left[\mu_{1}\left(S_{j}^{k+1}\right), \mu_{2}\left(S_{j}^{k+1}\right), \ldots \ldots \ldots \ldots \ldots \mu_{n}\left(S_{j}^{k+1}\right)\right]$.

The optimum switching state that minimizes both objective functions simultaneously is given by the maximum value of the $\mu_{D}$ and is given by

$$
S_{o p t}^{k+1}=\arg \max \left[\mu_{D}\left(S_{j}^{k+1}\right)\right]
$$

\subsection{Algorithm calculation example}

A two-level inverter can generate seven distinct voltage vectors as the voltage vectors; $u_{0}$ and $u_{7}$ both represent zero voltage vector. In the present work all eight possible switching states of the inverter voltage vectors $u_{s}=$ $\left[u_{0}, u_{1}, u_{2}, u_{3}, u_{4}, u_{5}, u_{6}, u_{7}\right]$ are considered. The cost functions $g_{1}$ and $g_{2}$ as given in Eq. (14) are evaluated for all possible voltage vectors. The voltage vector that minimizes both the objective functions simultaneously is chosen as the optimized switching state. The calculation algorithm using the conventional method is shown in figure 5a. The calculation example of optimal switching state using weighting factor is shown in table 1.

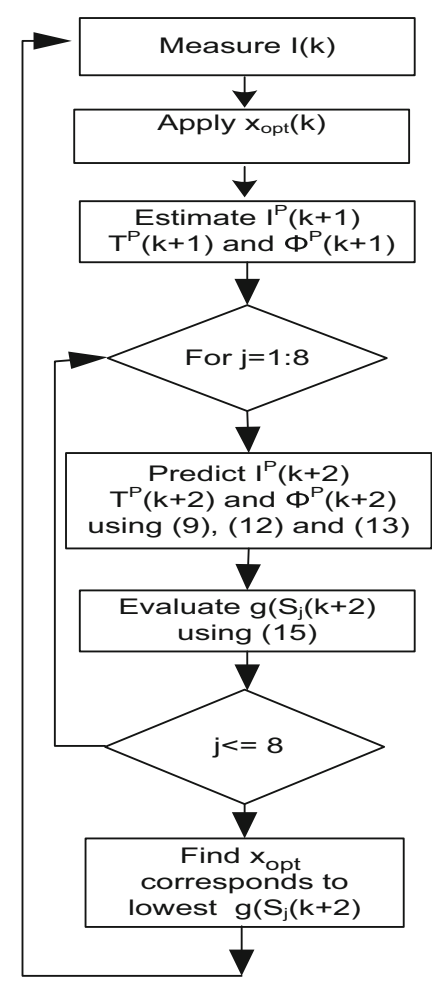

(a)

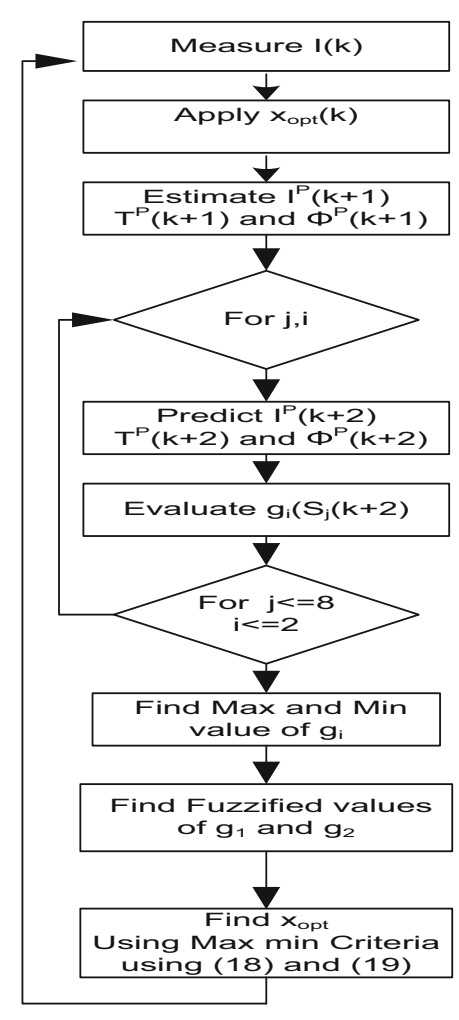

(b)

Figure 5. (a) Conventional approach and (b) FMCDM algorithm. 
Table 1. Optimum switching state selection using weighting factors.

\begin{tabular}{lcll}
\hline Switching state & $g_{1}$ & $g_{2}$ & $g=g_{1}+\lambda g_{2}$ \\
\hline 0 & 0.76 & 0.0025 & 0.81 \\
1 & 1.01 & 0.0108 & 1.23 \\
2 & 0.05 & 0.0041 & $\mathbf{0 . 1 3}$ \\
3 & 0.31 & 0.0092 & 0.5 \\
4 & 0.51 & 0.0158 & 0.83 \\
5 & 1.57 & 0.009 & 1.76 \\
6 & 1.83 & 0.0044 & 1.92 \\
\hline
\end{tabular}

Bold value indicates optimized switching state

Table 2. Optimum switching state selection using FMCDM.

\begin{tabular}{lcclll}
\hline Switching state & $g_{1}$ & $g_{2}$ & $\mu_{1}$ & $\mu_{2}$ & $\mu_{D}$ \\
\hline 0 & 0.76 & 0.0025 & 0 & 1 & 0 \\
1 & 0.22 & 0.0108 & 0.79 & 0.38 & 0.38 \\
2 & 0.08 & 0.0041 & 1 & 0.88 & $\mathbf{0 . 8 8}$ \\
3 & 0.19 & 0.0092 & 0.84 & 0.49 & 0.49 \\
4 & 0.32 & 0.0158 & 0.66 & 0 & 0 \\
5 & 0.19 & 0.009 & 0.84 & 0.51 & 0.51 \\
6 & 0.09 & 0.0044 & 0.99 & 0.87 & 0.87 \\
\hline
\end{tabular}

Bold value indicates optimized switching state

3.3a Fuzzy multi-criteria decision making: For fuzzy multicriteria decision making, the cost functions $g_{1}$ and $g_{2}$ are evaluated for each possible voltage vector. The functions $g_{1}$ and $g_{2}$, which represent, respectively, the torque error and the flux error for each possible voltage vector, are fuzzified using linear membership functions according to Eq. (17). The fuzzified torque error is represented as $\mu_{1}$ and the fuzzified flux error is represented as $\mu_{2}$ as shown in table 2 . The optimized switching state is calculated using the maxmin fuzzy inference method as explained in Eqs. (18) and (19). The optimized switching state for FMCDM is 2, which is calculated by taking the minimum of the $\mu_{1}$ and $\mu_{2}$, which is $\mu_{D}$, and then taking the maximum of the $\mu_{D}$ column in table 2. The algorithm for optimal switching state is shown in figure $5 \mathrm{~b}$. The numerical calculation example is shown in table 2.

\section{Experimental set-up}

The real-time experiments are carried out on a $2.2 \mathrm{~kW}$ slip ring induction motor using dSPACE (DS-1104). The induction motor is driven by a three-phase, two-level voltage source inverter using an intelligent power module (IPM). The IPM contains the gate drive mechanism, six IGBTs and the protection circuits. The motor currents are measured by Hall-effect current sensors and are acquired through a 12-bit analog to digital converters. The rotor position is measured using a 512 pulses/revolution quadrature encoder and is fed to the DSP through incremental encoder interface. A hardware schematic for real-time implementation is shown in figure 6 . The induction machine parameters determined using conventional no-load and blocked rotor tests are given in the appendix. The sampling time for the PTC algorithm is taken as $100 \mu$ s and a slow sampling time of $5 \mathrm{~ms}$ has been chosen for the speed control loop.

\section{Results and discussion}

\subsection{Simulation results}

A computer simulation of the proposed method is done using Matlab/Simulink. In order to have a fair comparison between the simulation and experimental results, the induction motor is modelled using the parameters obtained from the conventional test and then the proposed algorithm is implemented for predictive torque and flux control.

Induction motor parameters are given in the appendix. The torque and flux of the induction machine are controlled using (i) weighting factors and (ii) fuzzy multi-criteria decision making. The simulation results of the proposed FMCDM for two objective functions are shown in figures. 7 and 8 . The simulation results of stator current and electric torque at rated speed $(148 \mathrm{rad} / \mathrm{s})$ in the steady state at $50 \%$ of the rated load are shown in figure 7 . The stator flux is nominal at $0.76 \mathrm{~Wb}$. The torque and speed response are obtained during steady state. Current waveforms with small total harmonic distortion (THD) of $2.27 \%$ are

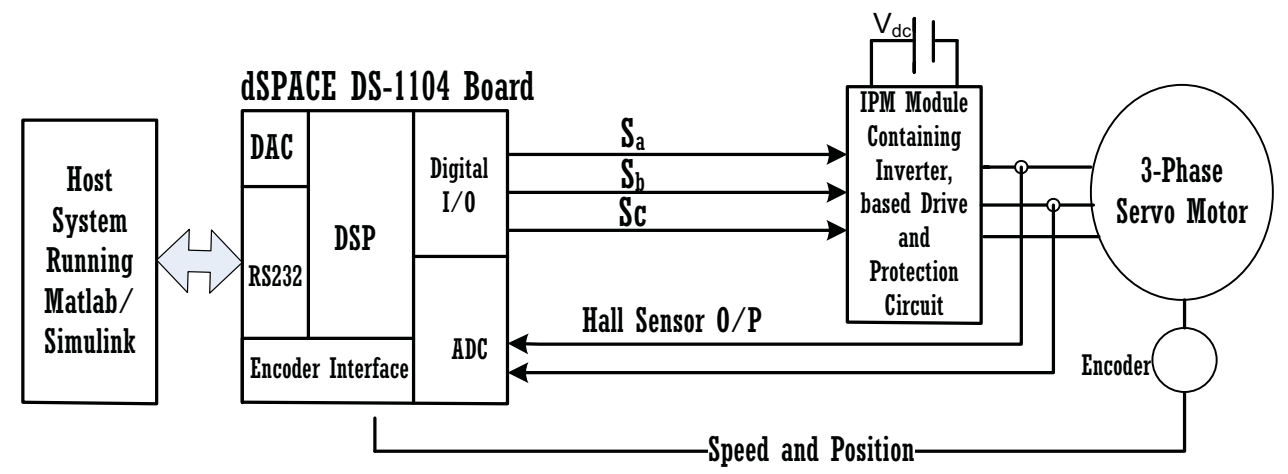

Figure 6. Hardware schematic for real-time implementation. 

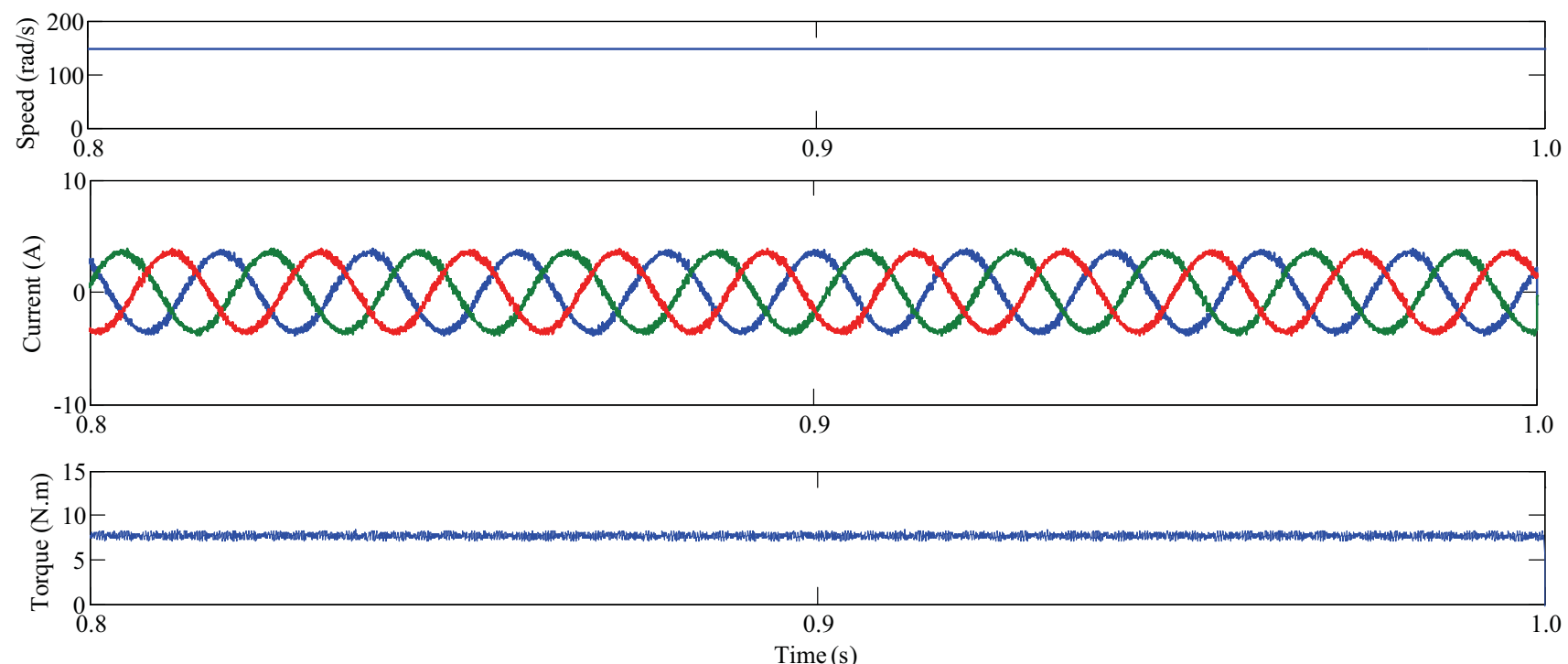

Figure 7. PTC of IM at rated speed using FMCDM: speed, stator current and electric torque in steady state at $50 \%$ of the rated load.

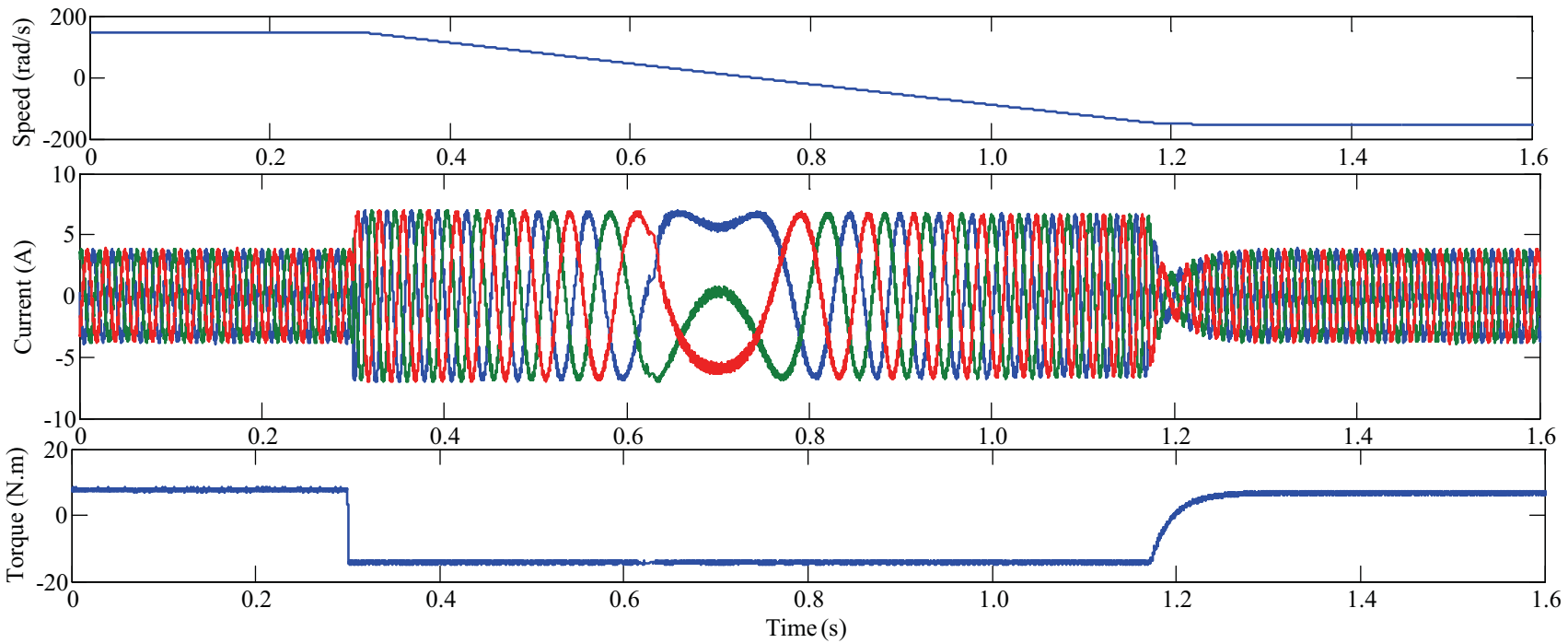

Figure 8. PTC of IM using FMCDM in transient state: speed, stator current and electric torque during speed reversal at $50 \%$ of the rated load.

obtained with the proposed approach. The average switching frequency, which is calculated using Eq. (20), is $3.3 \mathrm{kHz}$ :

$$
\begin{array}{r}
F_{s}=\text { total number of switchings for } 6 \text { semiconductor } \\
\text { switches in finite } \text { timet }_{p} / 6 t_{p} .
\end{array}
$$

The torque and speed response during speed reversal is shown in figure 8 . The reference speed has been changed from 148 to $-148 \mathrm{rad} / \mathrm{s}$; the stator current and electric torque are shown in figure 8 . The stator flux is maintained at a nominal value that produces good current waveforms with small THD of $2.27 \%$. The torque and stator flux ripples using the proposed strategy are $13.47 \%$ and $1.92 \%$, respectively. The response of the step set point change to the torque is shown in figure 9. A summary of the simulation results is presented in table 3 .

\subsection{Experimental results}

The motor is operated at the rated speed of $148 \mathrm{rad} / \mathrm{s}$ and at $50 \%$ of the nominal load for all the implemented control 


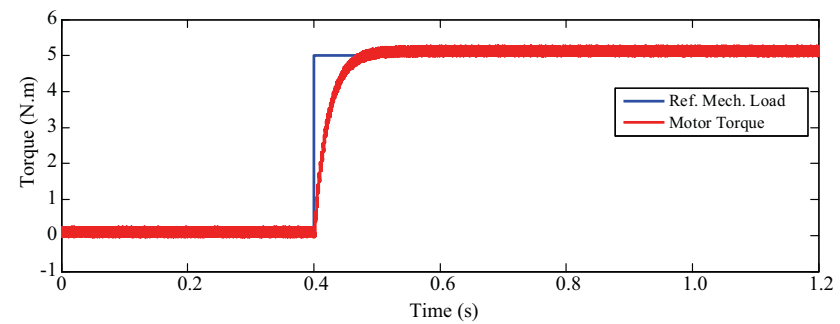

Figure 9. PTC of IM using FMCDM: step response of electric torque.

techniques. The experimental results of speed, stator current, torque, current harmonics and stator flux for the proposed approach are shown in figure 10. The current THD is $3.50 \%$, calculated using Fluke 434B, the three-phase power quality analyser. The stator flux ripples, torque ripples and the average switching frequency for the proposed control strategy are $3.52 \%, 18.43 \%$ and $3.68 \mathrm{kHz}$, respectively. The experimental results of the conventional method using weighting factors are shown in figure 11. The calculated current THD for the conventional PTC strategy is 5.7\%. The stator flux ripples, torque ripples and the average switching frequency for the proposed control strategy are $4.02 \%, 16.72 \%$ and $4.21 \mathrm{kHz}$, respectively.

The average execution time calculated using the dSPACE profiler for the proposed approach, $21.80 \mu \mathrm{s}$, is slightly higher as compared with average execution time for the conventional PTC, which is $16.20 \mu$ s.

\subsection{Algorithm execution time and complexity discussion}

Two multiple objectives optimization algorithms are implemented. The data flow diagram for the computational complexity is shown in figure 12 . For conventional PTC algorithm the weighting factors are calculated in an off-line manner. As clear from the data flow diagram in figure 12 , once the weighting factors are determined the conventional PTC algorithm takes less time to execute in real time. On a dSPACE DS-1104 platform, it took approximately $16.20 \mu$ s to execute the entire algorithm. The FMCDM requires the determination of maximum and minimum element of the two arrays, which is computationally more demanding as compared with the evaluation of single cost function in conventional method. The computation time for FMCDM depends upon the fuzzification method and the inference mechanism used. The linear fuzzification method is used to have a low computational burden. Once the torque error and flux errors are fuzzified, the optimized switching state is calculated by applying the max-min fuzzy inference method. On the DS-1104 platform the FMCDM took approximately $21.80 \mu$ s to run the entire algorithm.

\section{Conclusion}

The proposed FMCDM is used as an alternative to the conventional weighting-factor-based approach for multiple objective optimizations in the predictive torque control of an induction machine drive; as a result the weighting factor tuning is completely avoided and is replaced by a systematic and simple approach. Although the FMCDM approach is slightly more computationally demanding as compared with the conventional PTC, it is verified that the proposed algorithm can be implemented with the available hardware. The simulation and experimental tests conducted on a $2.2 \mathrm{~kW}$ IM have shown that the FMCDM offers better performance as compared with the conventional PTC in terms of current THD and flux ripples. Also the FMCDM method is easy to implement as compared with the conventional method and can be used in other similar applications where multiple objectives are required to be optimized simultaneously like predictive control of IM drive fed through a matrix converter, predictive current control of a NPC inverter and predictive control of a front end rectifier. Also, in the ranking-based method the actual value of the cost function is replaced by rank; hence comparison may not reflect how far or close two adjacent ranked switching functions are. Same ranks for two objective functions are tough to resolve as they may have two different cost function values.

Table 3. Performance comparison of the implemented techniques.

\begin{tabular}{|c|c|c|c|c|}
\hline \multirow[b]{2}{*}{ Performance index } & \multicolumn{2}{|c|}{ Simulation results } & \multicolumn{2}{|c|}{ Experimental results } \\
\hline & Conventional PTC & FMCDM & Conventional PTC & FMCDM \\
\hline THD of stator current & $3.35 \%$ & $2.27 \%$ & $5.7 \%$ & $3.50 \%$ \\
\hline Torque ripple & $13.31 \%$ & $13.47 \%$ & $16.72 \%$ & $18.43 \%$ \\
\hline Stator flux ripple & 0.0319 & 0.0192 & $0.0402 \mathrm{~Wb}$ & $0.0352 \mathrm{~Wb}$ \\
\hline Average execution time & N/A & $16.20 \mu \mathrm{s}$ & $21.80 \mu \mathrm{s}$ & \\
\hline Average switching frequency & $4.10 \mathrm{kHz}$ & $3.32 \mathrm{kHz}$ & $4.21 \mathrm{kHz}$ & $3.68 \mathrm{kHz}$ \\
\hline
\end{tabular}


(a)

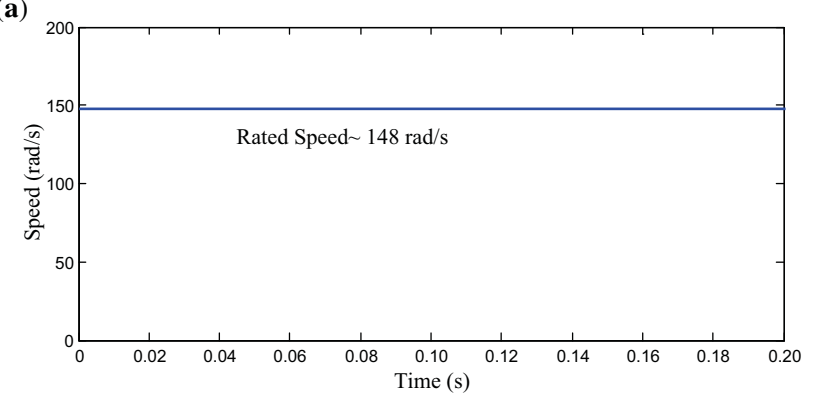

(b)

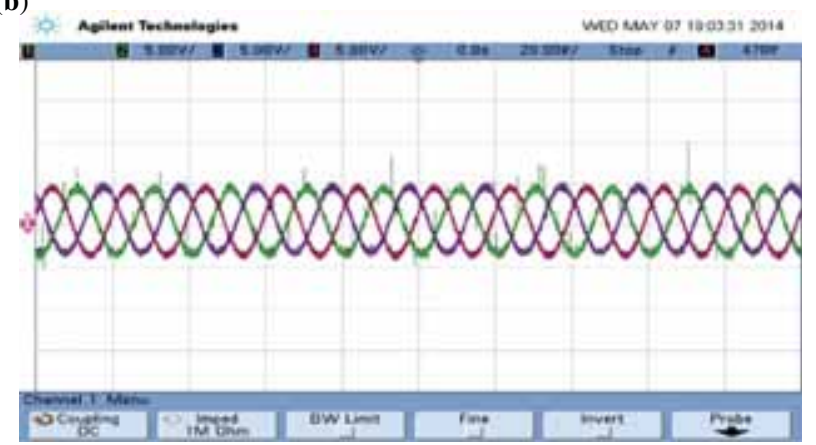

(c)

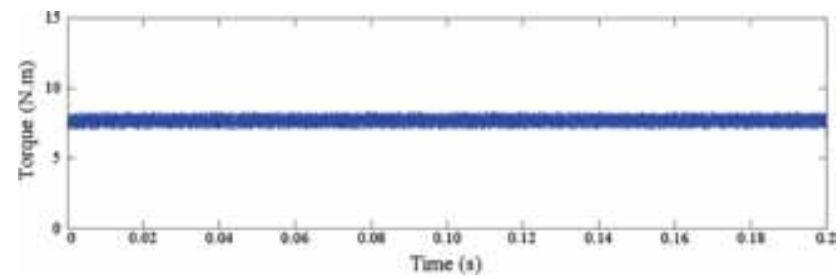

(d)

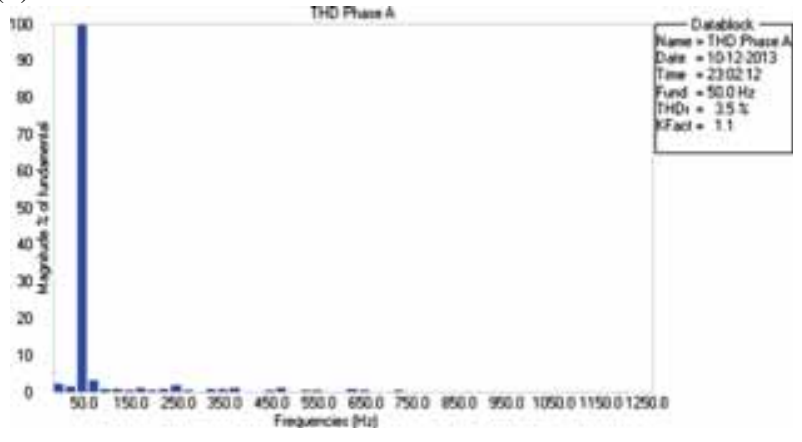

Figure 10. Experimental test results of FMCDM approach: (a) speed, (b) stator current, (c) torque and (d) current THD of an induction machine running at rated speed and $50 \%$ of the nominal load.

The computational complexity of the branch-and-boundalgorithm-based method increases manifolds when more than two objective functions are considered and the objective functions are of varying degree of importance. The FMCDM on the other hand can be easily extended to the multi- (a)

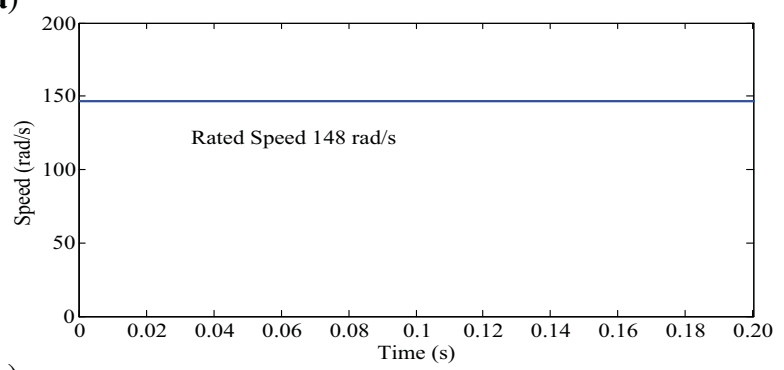

(b)

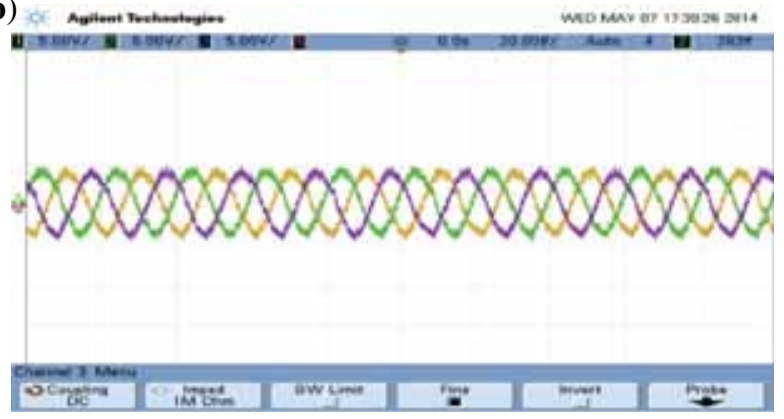

(c)

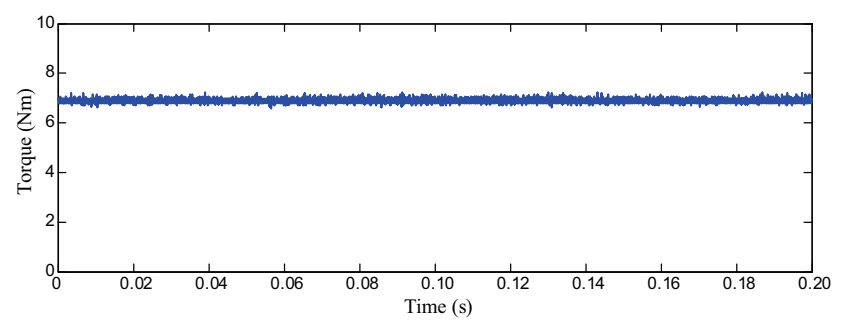

(d)

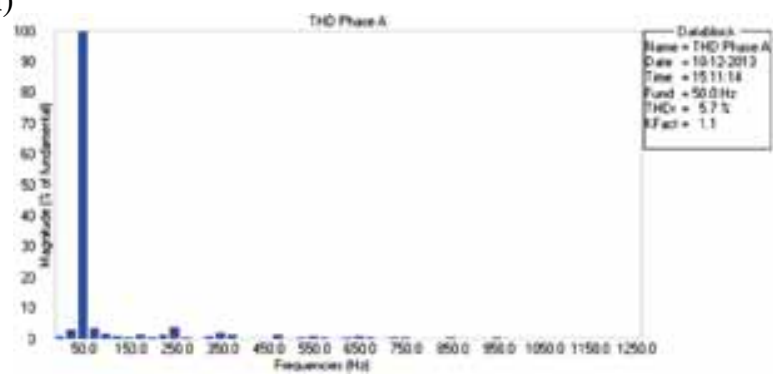

Figure 11. Experimental test results of conventional method: (a) speed, (b) stator current, (c) torque and (d) current THD of an induction machine running at rated speed and $50 \%$ of the nominal load.

objective optimization even when the objective functions are of varying degree of importance. The proposed method can be easily extended to further enhance the performance of the drive with neutral point clamped inverter, where there are inherently more than two objective functions. 


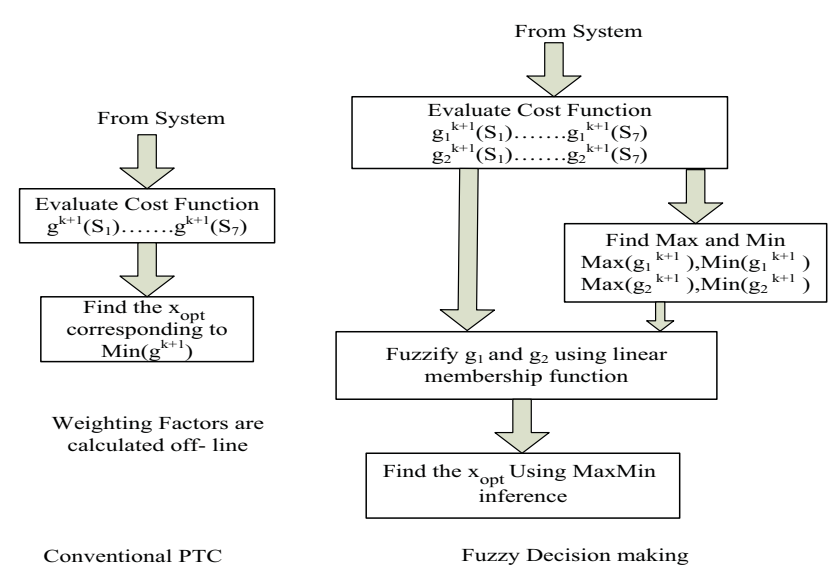

Figure 12. Data flow diagram for the implemented algorithms.

\section{Appendix}

Induction machine parameters used for simulation and experimental tests

\begin{tabular}{lc}
\hline Parameter & Value \\
\hline$R_{s}$ & $5.46 \Omega$ \\
$L_{s}$ & $0.3643 \mathrm{H}$ \\
$R_{r}$ & $2.68 \Omega$ \\
$L_{r}$ & $0.3643 \mathrm{H}$ \\
$L_{m}$ & $0.34 \mathrm{H}$ \\
$\omega_{\text {nom }}$ & $1410 \mathrm{RPM}$ \\
$T_{\text {nom }}$ & $14 \mathrm{Nm}$ \\
$P_{\text {nom }}$ & $2.2 \mathrm{~kW}$ \\
\hline
\end{tabular}

\section{References}

[1] Takahashi I and Noguchi T 1986 A new quick-response and high efficiency control strategy of an induction machine. IEEE Trans. Ind. Appl. 22(5): 820-827

[2] Takahashi I and Ohmori Y 1989 High-performance direct torque control of an induction motor. IEEE Trans. Ind. Appl. 25(2): 257-264

[3] Idris N R N, Toh C L and Elbuluk M E 2006 A new torque and flux controller for direct torque control of induction machines. IEEE Trans. Ind. Appl. 42(2): 1358-1366

[4] Casadei D, Profumo F, Serra An G and Tani A 2002 FOC and DTC: two viable schemes for induction motors torque control. IEEE Trans. Power Electron. 17(5): 779-787

[5] Lai Y S and Chen J H 2001 A new approach to direct torque control of induction motor drives for constant inverter switching frequency and torque ripple reduction. IEEE Trans. Energy Convers. 16(3): 220-227

[6] Lee K B and Blaabjerg F 2008 Sensorless DTC-SVM for induction motor driven by a matrix converter using a parameter estimation strategy. IEEE Trans. Ind. Electron. 55(2): 512-521

[7] Miranda H, Cortes P, Yuz J and Rodriguez J 2009 Predictive torque control of an induction machine based on state space models. IEEE Trans. Ind. Electron. 56(6): 1916-1924

[8] Rodriguez J, Kennel M, Espinoza J R, Trincado M, Silva C A and Rojas C A 2009 High performance control strategies for electrical drives: an experimental assessment. IEEE Trans. Ind. Electron. 59(2): 812-819

[9] Scoltock J, Geyer T and Madawala U K 2010 A comparison of model predictive control schemes for MV induction motor drives. IEEE Trans. Ind. Inform. 9(2): 909-916

[10] Cortes P, Kouro S, La Rocca B, Vargas R, Rodriguez J, Leon J I, Vazquez S and Franquelo L G 2009 Guidelines for weighting factors design in Model Predictive Control of power converters and drives. In: Proceedings of the IEEE ICIT Conference, pp. 1-7. Gippsland, Victoria, Australia.

[11] Rojas C A, Rodriguez J, Villarroel F, Espinoza J R, Silva C A and Trincado M 2013 Predictive torque and flux control without weighting factors. IEEE Trans. Ind. Electron. 60(2): 681-690

[12] Saaty T L 1980 The analytic hierarchy process. New York: McGraw Hill. Revised international edition, Pittsburgh: RWS Publications

[13] Alam N A, Md Lipia T F, Hasina M A A and Ullah A M M S 2011 Algorithms for fuzzy multi expert multi criteria decision making (ME-MCDM). Knowl. Based Syst. 24(3): 367-377

[14] Buckley J J 1984 The multiple judge, multiple criteria ranking problem: a fuzzy set approach. Fuzzy Sets Syst. 13(I): 25-37

[15] Chen Y H, Wang T C and Wuc C Y 2011 Multi-criteria decision making with fuzzy linguistic preference relations. Appl. Math. Model. 35(3): 1322-1330

[16] Yager R R 1978 Fuzzy decision making including unequal objectives. Fuzzy Sets Syst. 1: 87-98

[17] Holtz J 1995 The dynamic representation of AC drive system by complex signal flow graphs. In: Proceedings of IEEE ISIE'94, pp. 1-6. Bologna

[18] Kumar V, Gaur P and Mittal A P 2014 High performance predictive current control of a three phase VSI: an experimental assessment. Sadhana 39(6): 1295-1310

[19] Rodriguez J and Cortes P 2012 Predictive control of power converters and electrical drives. New York: John Wiley \& Sons

[20] Bellman R E and Zadeh L A 1970 Decision making in fuzzy environment. Manage. Sci. 17(4): B141-B164

[21] Bouafia A, Krim F and Gaubert J 2011 Fuzzy logic based switching state selection for direct power control of three phase PWM rectifier. IEEE Trans. Ind. Inform. 7(2): 204-211 